\title{
Immunohistochemistry for estrogen and progesterone receptors in the distinction of primary and metastatic mucinous tumors in the ovary: an analysis of 124 cases
}

\author{
Russell Vang ${ }^{1,4}$, Allen M Gown ${ }^{2}$, Todd S Barry ${ }^{2}$, Darren T Wheeler ${ }^{3, *}$ and \\ Brigitte M Ronnett ${ }^{1,4}$
}

${ }^{1}$ Department of Pathology, Division of Gynecologic Pathology, The Johns Hopkins University School of Medicine, Baltimore, MD, USA; ${ }^{2}$ PhenoPath Laboratories, Seattle, WA, USA; ${ }^{3}$ Armed Forces Institute of Pathology (Department of GYN \& Breast Pathology), Washington, DC, USA and ${ }^{4}$ Department of Gynecology and Obstetrics, The Johns Hopkins University School of Medicine, Baltimore, MD, USA

\begin{abstract}
Estrogen (ER) and progesterone receptor (PR) expression in primary ovarian mucinous tumors and the utility of these markers for distinguishing metastatic mucinous carcinomas in the ovary from primary ovarian mucinous tumors have not been extensively investigated. Immunohistochemical studies were performed on 124 mucinous tumors, including $\mathbf{5 2}$ primary ovarian tumors (30 atypical proliferative (borderline) mucinous tumors of gastrointestinal type, 11 atypical proliferative (borderline) mucinous tumors of seromucinous (endocervicallike) type, and 11 invasive mucinous carcinomas of usual (gastrointestinal) type) and 72 metastatic mucinous carcinomas in the ovary (primary sites: colorectum (24), pancreas (13), endocervix (eight), stomach (four), gallbladder/bile duct (four), appendix (four), and unknown (15)). All atypical proliferative mucinous tumors of gastrointestinal type, primary ovarian mucinous carcinomas, and metastatic mucinous carcinomas were negative for ER and PR with the exception of three metastatic endocervical adenocarcinomas which exhibited only weak expression of ER without PR. All atypical proliferative mucinous tumors of seromucinous type expressed ER to some degree and seven had some expression of PR. Immunohistochemical assessment of hormone receptor expression is of no value in distinguishing the common types of primary ovarian mucinous tumors (atypical proliferative mucinous tumors of gastrointestinal type and mucinous carcinomas of usual type) from the vast majority of mucinous carcinomas metastatic to the ovary. The above observations on hormone receptor expression in primary ovarian mucinous tumors support the concept that atypical proliferative (borderline) mucinous tumors of gastrointestinal and seromucinous (endocervical-like) types are distinctive tumors.
\end{abstract}

Modern Pathology (2006) 19, 97-105. doi:10.1038/modpathol.3800510; published online 11 November 2005

Keywords: ovary; mucinous tumor; mucinous carcinoma; metastases; estrogen receptor; progesterone receptor

Among ovarian epithelial tumors, the mucinous tumors pose the greatest difficulty with regard to distinction of primary from metastatic tumors. The primary ovarian mucinous tumors, including the atypical proliferative (borderline) tumors and carci-

Correspondence: Dr R Vang, MD, Department of Pathology, Division of Gynecologic Pathology, The Johns Hopkins Hospital, Weinberg Bldg., Room 2242, 401 North Broadway, Baltimore, MD 21231, USA.

E-mail: rvang1@jhmi.edu

*Current address: Quest Diagnostics Inc., Las Vegas, NV, USA. Received 27 July 2005; revised 30 September 2005; accepted 3 October 2005; published online 11 November 2005 nomas, and metastatic mucinous carcinomas in the ovaries are usually easily distinguished when they exhibit characteristic gross and microscopic features. The primary tumors are typically large (usually greater than $15 \mathrm{~cm}$ ), unilateral multicystic tumors with smooth capsules and are most often unassociated with extraovarian disease. The carcinomas most often arise in association with atypical proliferative (borderline) tumors and while they can exhibit destructive stromal invasion, they frequently display confluent glandular or expansile, rather than infiltrative, patterns of invasion. In contrast, typical features of metastatic mucinous carcinomas in the ovary that distinguish them from primary tumors include bilaterality, smaller size (often less 
than $10 \mathrm{~cm}$ ), ovarian surface involvement, a nodular pattern of involvement, and an infiltrative pattern of stromal invasion. ${ }^{1-3}$ However, some metastatic mucinous carcinomas can manifest one or more features suggesting a primary ovarian tumor, including presentation as a large unilateral tumor in the absence of a known extraovarian primary site and formation of a multicystic tumor exhibiting confluent glandular or expansile, rather than infiltrative, patterns of invasion, thus simulating primary ovarian atypical proliferative (borderline) mucinous tumors with intraepithelial carcinoma or welldifferentiated mucinous carcinomas of confluent glandular type. ${ }^{4-10}$ Despite recognition of the ability of these metastases to simulate primary ovarian tumors and recent studies providing refined diagnostic criteria for ovarian mucinous tumors, ${ }^{1,2,11,12}$ the problem of distinguishing these tumors persists. This problem is compounded by the fact that in routine practice metastatic mucinous carcinomas are more common than primary ovarian mucinous carcinomas, ${ }^{3}$ with those of gastrointestinal and pancreaticobiliary tract origin being the most commonly encountered types. ${ }^{1,3}$

When characteristic gross and microscopic features are lacking, ancillary studies are often necessary to distinguish primary ovarian mucinous tumors from metastases. Unfortunately, only a limited number of immunohistochemical markers has been shown to be useful in this distinction, including cytokeratins 7 and 20 and Dpc4. In addition, the utility of these markers is restricted based on the primary site of origin under consideration. Thus, cytokeratins 7 and 20 are useful for distinction of ovarian endometrioid and mucinous tumors from metastatic lower intestinal tract carcinomas (most colorectal and appendiceal carcinomas) but not from many other metastatic carcinomas (including pancreaticobiliary, gastric, endocervical, endometrial and pulmonary carcinomas), whereas Dpc4 is useful in the distinction of ovarian mucinous tumors from pancreatic carcinomas in only $\sim 50 \%$ of cases. ${ }^{13-19}$ Owing to these limitations and restrictions, identification of additional markers to assist in the distinction of these mucinous tumors would be valuable. Primary ovarian epithelial tumors, particularly those of serous and endometrioid types, are known to often express hormone receptors. ${ }^{16,20-32}$ Thus, one could speculate that other subtypes of ovarian epithelial tumors, such as the mucinous type, might also express estrogen receptor $(\mathrm{ER})$ and progesterone receptor $(\mathrm{PR})$ and that these markers might serve to distinguish primary and metastatic mucinous tumors in the ovary. Since data in the literature on expression of ER and PR in primary ovarian mucinous tumors and in mucinous carcinomas of various extraovarian sites is limited and conflicting, ${ }^{16,20-27,33-51}$ we analyzed a large number of rigorously classified tumors to assess the utility of these markers in the distinction of these tumors.

\section{Materials and methods}

\section{Case Selection}

A total of 124 mucinous tumors involving the ovary were selected from the surgical pathology files of The Johns Hopkins Hospital and the Armed Forces Institute of Pathology (Department of GYN \& Breast Pathology) from 1990 to 2005. In all, 87 tumors (31 primary, 56 metastatic) were routine in-house cases and 37 were consultation cases (21 primary, 16 metastatic). A total of 52 cases were primary ovarian mucinous tumors, including 30 atypical proliferative (borderline) mucinous tumors of gastrointestinal type, 11 atypical proliferative seromucinous tumors (mucinous borderline tumors of endocervical-like type), and 11 invasive mucinous carcinomas of usual type (referring to the 'common' type of ovarian mucinous carcinomas having gastrointestinal-type or nonspecific mucinous differentiation rather than the rare mucinous carcinomas of seromucinous (endocervical-like) type). In all, 72 cases were metastatic mucinous carcinomas involving the ovary, with primary sites including colorectum (24), pancreas (13), endocervix (eight), stomach (four), gallbladder/biliary tract (four), appendix (four), and unknown primary sites (15). The metastases classified as of 'unknown primary site' exhibited characteristic gross and microscopic features of metastases (with morphologic features, and in some cases immunohistochemical features, most often implicating the gastrointestinal tract as the primary site), ${ }^{52}$ but a specific primary site had not been established in these cases. Clinical data, data from imaging studies, and pathologic (gross and microscopic) criteria $^{2}$ were used to rigorously classify the tumors as primary or metastatic.

\section{Immunohistochemistry}

Immunohistochemical stains were performed at both PhenoPath Laboratories and The Johns Hopkins Hospital using formalin-fixed, paraffinembedded tissue sections. The manufacturer, clone, dilution, and pretreatment details for each primary antibody are summarized in Table 1. Unstained sections were deparaffinized and rehydrated prior to subjecting them to antigen retrieval using protocols optimized for each antibody.

The immunohistochemical method used at PhenoPath Laboratories was performed as follows. Following pretreatment, primary antibodies (ER and PR) were applied to respective sections and incubated for $30 \mathrm{~min}$ at room temperature. SP-1 and SP-2 rabbit monoclonal antibodies for ER and PR, respectively, were employed because preliminary evidence suggests that they are more sensitive than the mouse monoclonal antibodies. ${ }^{53,54}$ Antibody localization was achieved by incubating slides for $30 \mathrm{~min}$ at room temperature in Envision + -labeled polymer (DakoCytomation, Carpinteria, CA, USA) 
Table 1 Details of immunohistochemical analysis

\begin{tabular}{|c|c|c|c|c|}
\hline Antibody & Manufacturer & Clone & Dilution & Pretreatment \\
\hline $\mathrm{ER}^{\mathrm{a}}$ & NeoMarkers & SP-1 & $1: 500$ & Microwave pressure cooker, $8 \mathrm{~min}, 10 \mathrm{mM}$ citrate buffer (pH 6.0) \\
\hline $\mathrm{ER}^{\mathrm{b}}$ & Ventana & $6 \mathrm{~F} 11$ & Prediluted & $\begin{array}{l}\text { CC1 antigen retrieval solution (Ventana) (prediluted; } \mathrm{pH} \text { 8.0), performed on } \\
\text { autostainer, } 95^{\circ} \mathrm{C}, 30 \mathrm{~min}\end{array}$ \\
\hline $\mathrm{PR}^{\mathrm{a}}$ & NeoMarkers & SP-2 & $1: 500$ & Microwave pressure cooker, $8 \mathrm{~min}, 10 \mathrm{mM}$ citrate buffer (pH 6.0) \\
\hline $\mathrm{PR}^{\mathrm{b}}$ & Ventana & 16 & Prediluted & $\begin{array}{l}\text { CC1 antigen retrieval solution (Ventana) (prediluted; } \mathrm{pH} \text { 8.0), performed on } \\
\text { autostainer, } 95^{\circ} \mathrm{C}, 30 \mathrm{~min}\end{array}$ \\
\hline
\end{tabular}

${ }^{\mathrm{a}}$ PhenoPath Laboratories.

bJohns Hopkins Hospital Immunohistochemistry Laboratory.

Table 2 Distribution of expression of ER and PR in primary ovarian mucinous tumors

\begin{tabular}{|c|c|c|c|c|c|c|c|c|c|c|}
\hline & \multicolumn{5}{|c|}{$E R^{\mathrm{a}}$} & \multicolumn{5}{|c|}{$P R^{\mathrm{a}}$} \\
\hline & 0 & $1+$ & $2+$ & $3+$ & $4+$ & 0 & $1+$ & $2+$ & $3+$ & $4+$ \\
\hline $\begin{array}{l}\text { Atypical proliferative mucinous } \\
\text { tumors, gastrointestinal type } \\
(n=30)\end{array}$ & $30(100 \%)$ & 0 & 0 & 0 & 0 & $30(100 \%)$ & 0 & 0 & 0 & 0 \\
\hline $\begin{array}{l}\text { Atypical proliferative } \\
\text { seromucinous tumors }(n=11)\end{array}$ & 0 & $2(18 \%)$ & $2(18 \%)$ & $2(18 \%)$ & $5(45 \%)$ & $4(36 \%)$ & $3(27 \%)$ & $1(9 \%)$ & $1(9 \%)$ & $2(18 \%)$ \\
\hline $\begin{array}{l}\text { Invasive mucinous carcinomas } \\
(n=11)\end{array}$ & $11(100 \%)$ & 0 & 0 & 0 & 0 & $11(100 \%)$ & 0 & 0 & 0 & 0 \\
\hline
\end{tabular}

${ }^{a}$ Staining distribution (percentage positive cells): $0: \leq 5 \% ; 1+: 6-25 \% ; 2+: 26-50 \% ; 3+: 51-75 \%$; and 4+; $76-100 \%$ (all reactions exhibited moderate to strong staining intensity).

using a Dako autostainer. The slides were then incubated for $10 \mathrm{~min}$ at $37^{\circ} \mathrm{C}$ in a solution containing $3 \%$ hydrogen peroxide and $3,3^{\prime}$-diaminobenzidine.

The immunohistochemical method used at The Johns Hopkins Hospital laboratory was performed as follows. Following pretreatment, primary mouse monoclonal antibody (ER and PR) was applied to respective sections and incubated for $32 \mathrm{~min}$ (ER) and $16 \mathrm{~min}$ (PR), respectively, at room temperature. Antibody localization was achieved by incubating slides for $16 \mathrm{~min}$ at room temperature in iVIEWlabeled conjugate (Ventana, Tucson, AZ, USA) using a Ventana autostainer (Benchmark XT). The slides were then incubated for $8 \mathrm{~min}$ at room temperature in a solution containing hydrogen peroxide (prediluted; Ventana) and 3,3'-diaminobenzidine.

\section{Interpretation and Scoring of Immunohistochemical Preparations}

Reactions were interpreted as positive based on nuclear staining. Immunohistochemical results were scored based on the percentage of cells showing expression: negative: $\leq 5 \%$; and positive: $>5 \%$. For descriptive purposes, the distribution of staining was semiquantitatively scored based on the percentage of positive cells: $0: \leq 5 \% ; 1+: 6-25 \% ; 2+: 26-$ $50 \% ; 3+: 51-75 \%$; and $4+; 76-100 \%$. Intensity of staining was noted but not used for scoring. Although immunohistochemical stains were performed in two different laboratories, tumors of the same type showed no notable differences in staining profiles between the laboratories.

\section{Results}

\section{Primary Ovarian Tumors (Table 2)}

Among all primary ovarian mucinous tumors evaluated, hormone receptor expression was restricted to the seromucinous tumors. In all, 11 (100\%) atypical proliferative (borderline) mucinous tumors of seromucinous-type expressed ER (Figure 1). The immunohistochemical score was $1+$ in two cases, $2+$ in two, $3+$ in two, and $4+$ in five. The intensity of expression was moderate to strong. Seven of 11 (64\%) seromucinous tumors expressed PR (Figure 1). The immunohistochemical score was 0 in four cases, $1+$ in three, $2+$ in one, $3+$ in one, and $4+$ in two. The intensity of expression was moderate to strong. Neither ER nor PR was expressed in 30 atypical proliferative mucinous tumors of gastrointestinal type (Figure 2) or in 11 invasive mucinous carcinomas. ER and PR expression were observed in normal ovarian stroma which served as an internal positive control.

\section{Metastatic Mucinous Carcinomas Involving the Ovary (Table 3)}

Three of eight (38\%) endocervical adenocarcinomas expressed ER (Figure 3). The immunohistochemical 
100
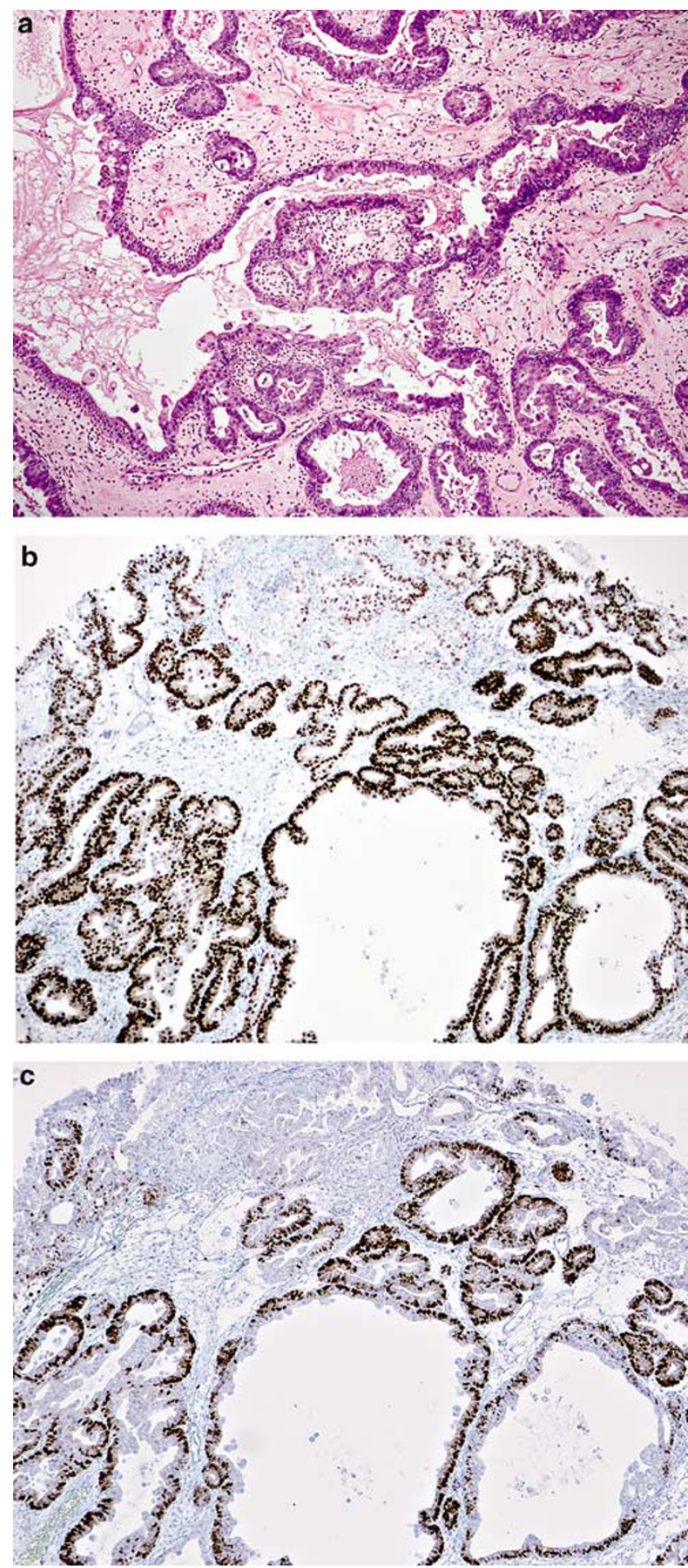

Figure 1 (a) Atypical proliferative (borderline) tumor of seromucinous (endocervical-like) type. (b) Tumor exhibits expression of ER (immunohistochemical score for the entire tumor was $4+$, with moderate to strong staining intensity). (c) Tumor exhibits expression of PR (immunohistochemical score for the entire tumor was $3+$, with moderate to strong staining intensity).

score was 0 in four tumors, $1+$ in one, $2+$ in one, and $4+$ in one. The intensity of expression was uniformly weak in those showing expression. PR was not expressed in any of these eight tumors.
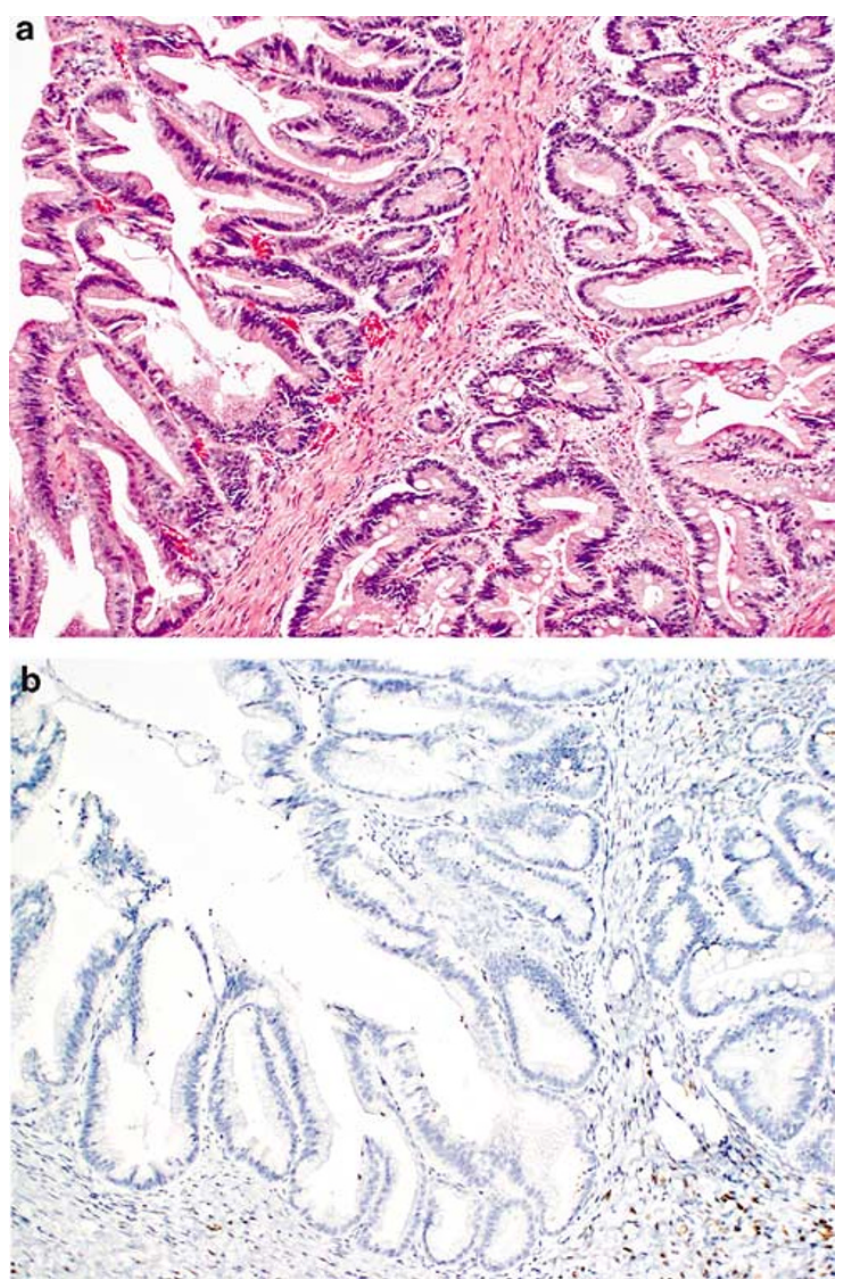

Figure 2 (a) Atypical proliferative (borderline) mucinous tumor of gastrointestinal type. (b) Tumor lacks expression of ER (ovarian stroma serves as internal positive control) and was also negative for PR (not shown).

Neither ER nor PR was expressed in the remaining metastatic tumors, including 24 colorectal adenocarcinomas, 13 pancreatic adenocarcinomas, four gastric adenocarcinomas, four gallbladder/biliary tract adenocarcinomas, four appendiceal adenocarcinomas, and 15 metastatic adenocarcinomas of unknown primary site. In cases in which normal ovarian stroma was present, staining for ER and PR was present and served as an internal positive control.

\section{Discussion}

Among the metastatic mucinous carcinomas evaluated in this study, neither ER nor PR expression was observed in any metastases of gastrointestinal tract origin, including those metastatic from the colorectum, pancreas, biliary tract, gallbladder, and appendix, or in metastases of unknown primary sites which were most likely also of gastrointestinal tract origin based on morphologic features. In other 
Table 3 Distribution of expression of ER and PR in metastatic mucinous carcinomas involving the ovary

\begin{tabular}{|c|c|c|c|c|c|c|c|c|c|c|}
\hline \multirow[t]{2}{*}{ Origin } & \multicolumn{5}{|c|}{$E R^{\text {a }}$} & \multicolumn{5}{|c|}{$P R^{\mathrm{a}}$} \\
\hline & 0 & $1+$ & $2+$ & $3+$ & $4+$ & 0 & $1+$ & $2+$ & $3+$ & $4+$ \\
\hline Colorectal $(n=24)$ & $24(100 \%)$ & 0 & 0 & 0 & 0 & $24(100 \%)$ & 0 & 0 & 0 & 0 \\
\hline Unknown $(n=15)$ & $15(100 \%)$ & 0 & 0 & 0 & 0 & $15(100 \%)$ & 0 & 0 & 0 & 0 \\
\hline Pancreatic $(n=13)$ & $13(100 \%)$ & 0 & 0 & 0 & 0 & $13(100 \%)$ & 0 & 0 & 0 & 0 \\
\hline Endocervical $(n=8)$ & $5(63 \%)$ & $1^{\mathrm{b}}(13 \%)$ & $1^{\mathrm{b}}(13 \%)$ & 0 & $1^{\mathrm{b}}(13 \%)$ & $8(100 \%)$ & 0 & 0 & 0 & 0 \\
\hline Gastric $(n=4)$ & $4(100 \%)$ & 0 & 0 & 0 & 0 & $4(100 \%)$ & 0 & 0 & 0 & 0 \\
\hline Gallbladder/biliary tract $(n=4)$ & $4(100 \%)$ & 0 & 0 & 0 & 0 & $4(100 \%)$ & 0 & 0 & 0 & 0 \\
\hline Appendiceal $(n=4)$ & $4(100 \%)$ & 0 & 0 & 0 & 0 & $4(100 \%)$ & 0 & 0 & 0 & 0 \\
\hline
\end{tabular}

${ }^{\mathrm{a}}$ Staining distribution (percentage positive cells): 0: $\leq 5 \% ; 1+:$ 6-25\%; 2+: $26-50 \%$; $3+$ : $51-75 \%$; and 4+; $76-100 \%$.

${ }^{\mathrm{b}}$ Weak staining intensity.

published studies, expression of hormone receptors in gastrointestinal and pancreaticobiliary adenocarcinomas varies markedly, with many studies demonstrating a lack of expression of ER and $\mathrm{PR}^{16,21,22,25,27,34,36-38,41,45,46,48,50}$ but others reporting expression of these markers. ${ }^{25,33,39,40,44,45,47-49,51,55}$ The reasons for the differing results in the latter studies are not apparent, but variation in immunohistochemical methods (including different antibodies and/or epitope retrieval methods), case selection, and tumor classification could be factors; however, the use of a more sensitive tyramine amplification technique accounts for increased apparent expression of ER in one study, ${ }^{25}$ no ER expression was found in any colorectal adenocarcinomas in the largest of the series, ${ }^{48}$ and our unpublished observations suggest that ER or PR expression in gastrointestinal and pancreatobiliary tract tumors is exceedingly rare.

The only metastases in our study exhibiting hormone receptor expression were a minority of metastatic endocervical adenocarcinomas, which demonstrated weak expression of ER without PR. This result is in keeping with other studies demonstrating a low frequency of hormone receptor expression in primary endocervical adenocarcinomas. ${ }^{56-61}$ Metastatic endocervical adenocarcinomas in the ovary usually simulate either primary ovarian endometrioid tumors or mucinous tumors of gastrointestinal (not seromucinous/endocervical-like) type. The infrequent expression of hormone receptors in endocervical adenocarcinomas, lack of expression of hormone receptors in both primary ovarian atypical proliferative (borderline) mucinous tumors of gastrointestinal type and ovarian mucinous carcinomas of usual type in this study, and frequent expression of hormone receptors in ovarian endometrioid tumors observed in other studies $^{16,24,26,31}$ indicate that ER/PR expression is most often useful only in the distinction of endocervical adenocarcinomas from primary ovarian endometrioid but not mucinous tumors. It is important to note that the application of ER/PR expression to an individual case for which the differential diagnosis concerns metastatic endocervical adenocarcinoma vs a primary ovarian tumor must be performed with awareness that interpretation depends on the type of differentiation exhibited by the tumor (mucinous vs endometrioid) and recognition that some endocervical adenocarcinomas can retain expression of hormone receptors. Thus, other ancillary techniques (p16 expression and human papillomavirus DNA detection) may be necessary for definitive distinction of these tumors. ${ }^{5}$

Metastatic mucinous carcinomas from the breast, endometrium, and lung were not included in this study since we did not have any retrievable cases with paraffin blocks available in our files. These types of metastatic mucinous carcinomas are rather uncommon and usually do not enter into the differential diagnosis of mucinous tumors involving the ovary. Hormone receptor expression is frequently observed in breast carcinomas, including mucinous/colloid and signet ring cell types, ${ }^{37,62-65}$ and mucinous carcinomas of the endometrium ${ }^{66}$ and could serve to distinguish metastases of these tumors from the common types of primary ovarian mucinous tumors. In particular, hormone receptor expression is of value for distinguishing the signet ring cell variant of lobular carcinoma from metastatic gastric and appendiceal signet ring cell carcinomas, which lacked hormone receptor expression in our study. Lung adenocarcinomas are usually negative for ER and PR, but expression has been reported in some studies. ${ }^{47,67,68}$

Among the primary ovarian mucinous tumors in this study, ER and PR expression were observed exclusively in atypical proliferative (borderline) mucinous tumors of seromucinous (endocervicallike) type; atypical proliferative (borderline) mucinous tumors of gastrointestinal type and primary ovarian invasive mucinous carcinomas of the usual type did not express ER or PR. Previous studies have reported a low frequency of ER and PR expression in atypical proliferative (borderline) mucinous tumors of gastrointestinal type $(0-14 \%)^{26,43,69}$ and variable expression of ER and PR in primary ovarian invasive mucinous carcinomas (ER in $0-70 \%, P R$ 
102
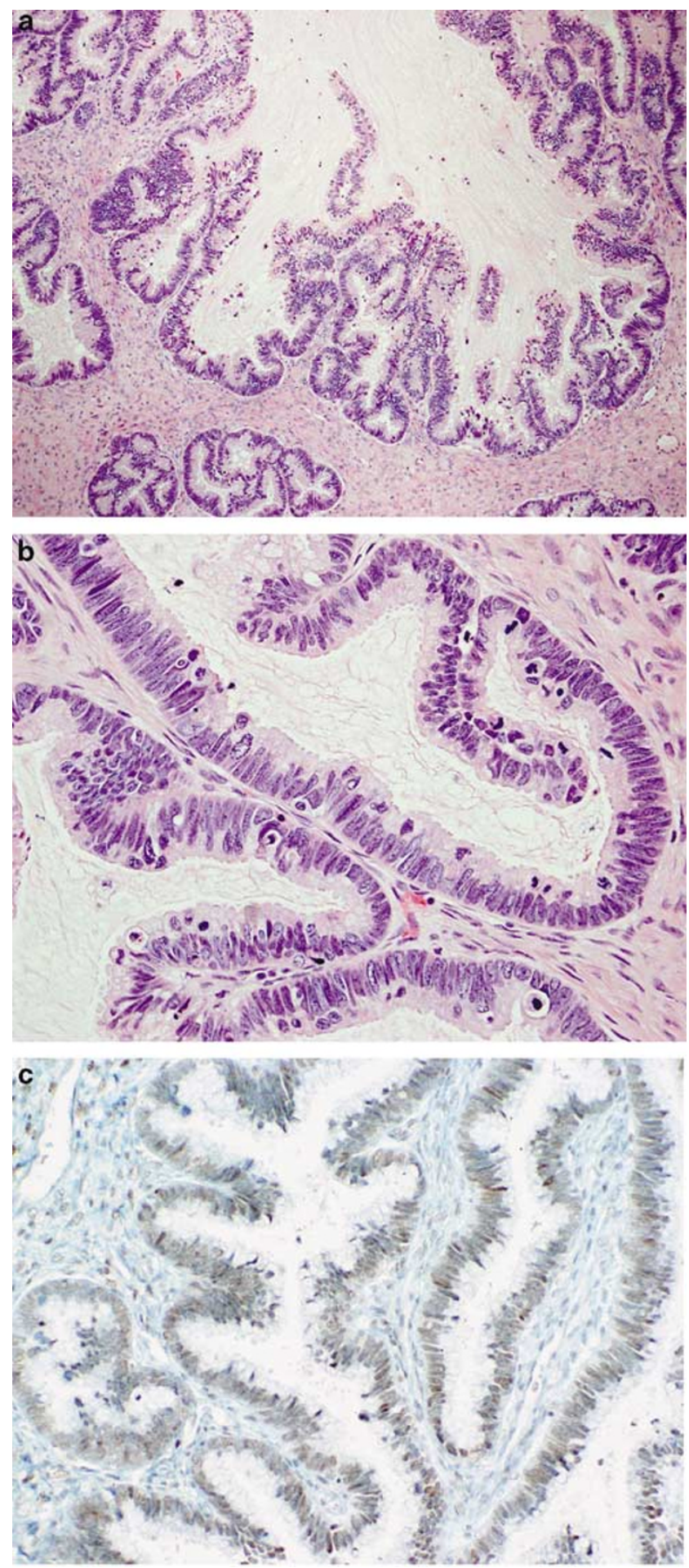

Figure 3 (a and b) Metastatic endocervical adenocarcinoma involving the ovary simulates an atypical proliferative (borderline) mucinous tumor of gastrointestinal type with intraepithelial carcinoma. The tumor lacks evidence of stromal invasion but exhibits notable nuclear atypia. Mucinous epithelium displays features characteristic of an HPV-related endocervical adenocarcinoma (nuclear atypia, numerous mitotic figures, and apoptotic bodies). (c) Tumor exhibits some expression of ER, which was uncommon among all tumors of this type (immunohistochemical score for the entire tumor was $4+$, with uniformly weak intensity). in $0-30 \%)^{16,23,24,26,35,42,43,69}$ In contrast, uniform expression of ER has been reported in a very limited number of seromucinous (endocervical-like) tumors, including both atypical proliferative (borderline) tumors and the rare carcinomas of this type. ${ }^{20,42}$ While ER expression can distinguish the relatively uncommon seromucinous tumors from most metastatic mucinous carcinomas, including most metastatic endocervical adenocarcinomas, seromucinous tumors are most commonly of the atypical proliferative type and are usually readily recognized as primary ovarian tumors due to their distinctive features. ${ }^{70-73}$ Metastatic mucinous carcinomas exhibiting deceptive patterns of invasion (confluent glandular or expansile rather than infiltrative) in the ovary usually simulate the more common atypical proliferative mucinous tumors of gastrointestinal type and mucinous carcinomas of usual type. Thus, the lack of ER and PR expression in both the common primary ovarian mucinous tumors and most metastatic mucinous carcinomas (including all those of gastrointestinal origin, which are the most common type) demonstrates that hormone receptor expression is not useful for distinction of these mucinous tumors in the ovary.

The above observations on hormone receptor expression in primary ovarian mucinous tumors support the concept that atypical proliferative (borderline) mucinous tumors of gastrointestinal and seromucinous (endocervical-like) types are distinctive tumors. ${ }^{74}$ Subclassification of these types based on morphology is occasionally problematic for pathologists who have limited experience with the uncommon seromucinous type, and thus, ER/PR expression may be useful in this regard. Shared expression of hormone receptors by atypical proliferative (borderline) serous and seromucinous tumors supports the notion that the seromucinous subtype is more closely related to the serous type than the gastrointestinal mucinous type and, in conjunction with morphologic features, justifies the designation 'seromucinous' ${ }^{73,74}$

In summary, hormone receptor expression is of no value in distinguishing atypical proliferative (borderline) mucinous tumors of gastrointestinal type and primary ovarian invasive mucinous carcinomas of usual type from the vast majority of mucinous carcinomas metastatic to the ovary. Additionally, lack of hormone receptor expression in primary ovarian mucinous carcinomas of usual type suggests there is no role for hormonal therapy in the management of these tumors.

\section{Acknowledgements}

We thank Patti Loykasek and Jana Hagen, MT (PhenoPath Laboratories, Seattle, WA, USA) for their technical assistance. 


\section{References}

1 Lee KR, Young RH. The distinction between primary and metastatic mucinous carcinomas of the ovary: gross and histologic findings in 50 cases. Am J Surg Pathol 2003;27:281-292.

2 Riopel MA, Ronnett BM, Kurman RJ. Evaluation of diagnostic criteria and behavior of ovarian intestinaltype mucinous tumors: atypical proliferative (borderline) tumors and intraepithelial, microinvasive, invasive, and metastatic carcinomas. Am J Surg Pathol 1999;23:617-635.

3 Seidman JD, Kurman RJ, Ronnett BM. Primary and metastatic mucinous adenocarcinomas in the ovaries: incidence in routine practice with a new approach to improve intraoperative diagnosis. Am J Surg Pathol 2003;27:985-993.

4 Daya D, Nazerali L, Frank GL. Metastatic ovarian carcinoma of large intestinal origin simulating primary ovarian carcinoma. A clinicopathologic study of 25 cases. Am J Clin Pathol 1992;97:751-758.

5 Elishaev E, Gilks CB, Miller D, et al. Synchronous and metachronous endocervical and ovarian neoplasms: evidence supporting interpretation of the ovarian neoplasms as metastatic endocervical adenocarcinomas simulating primary ovarian surface epithelial neoplasms. Am J Surg Pathol 2005;29: 281-294.

6 Lash RH, Hart WR. Intestinal adenocarcinomas metastatic to the ovaries. A clinicopathologic evaluation of 22 cases. Am J Surg Pathol 1987;11:114-121.

7 Ronnett BM, Kajdacsy-Balla A, Gilks CB, et al. Mucinous borderline ovarian tumors: points of general agreement and persistent controversies regarding nomenclature, diagnostic criteria, and behavior. Hum Pathol 2004;35:949-960.

8 Ronnett BM, Kurman RJ, Shmookler BM, et al. The morphologic spectrum of ovarian metastases of appendiceal adenocarcinomas: a clinicopathologic and immunohistochemical analysis of tumors often misinterpreted as primary ovarian tumors or metastatic tumors from other gastrointestinal sites. Am J Surg Pathol 1997;21:1144-1155.

9 Young RH, Hart WR. Metastases from carcinomas of the pancreas simulating primary mucinous tumors of the ovary. A report of seven cases. Am J Surg Pathol 1989;13:748-756.

10 Young RH, Scully RE. Ovarian metastases from carcinoma of the gallbladder and extrahepatic bile ducts simulating primary tumors of the ovary. A report of six cases. Int J Gynecol Pathol 1990;9: $60-72$.

11 Lee KR, Scully RE. Mucinous tumors of the ovary: a clinicopathologic study of 196 borderline tumors (of intestinal type) and carcinomas, including an evaluation of 11 cases with 'pseudomyxoma peritonei'. Am J Surg Pathol 2000;24:1447-1464.

12 Rodriguez IM, Prat J. Mucinous tumors of the ovary: a clinicopathologic analysis of 75 borderline tumors (of intestinal type) and carcinomas. Am J Surg Pathol 2002;26:139-152.

13 Cao D, Ji H, Ronnett BM. Expression of mesothelin, fascin, and prostate stem cell antigen in primary ovarian mucinous tumors and their utility in differentiating primary ovarian mucinous tumors from metastatic pancreatic mucinous carcinomas in the ovary. Int J Gynecol Pathol 2005;24:67-72.
14 Cathro HP, Stoler MH. Expression of cytokeratins 7 and 20 in ovarian neoplasia. Am J Clin Pathol 2002;117: 944-951.

15 Chu P, Wu E, Weiss LM. Cytokeratin 7 and cytokeratin 20 expression in epithelial neoplasms: a survey of 435 cases. Mod Pathol 2000;13:962-972.

16 Dionigi A, Facco C, Tibiletti MG, et al. Ovarian metastases from colorectal carcinoma. Clinicopathologic profile, immunophenotype, and karyotype analysis. Am J Clin Pathol 2000;114:111-122.

$17 \mathrm{Ji} \mathrm{H}$, Isacson C, Seidman JD, et al. Cytokeratins 7 and 20, Dpc4, and MUC5AC in the distinction of metastatic mucinous carcinomas in the ovary from primary ovarian mucinous tumors: Dpc4 assists in identifying metastatic pancreatic carcinomas. Int J Gynecol Pathol 2002;21:391-400.

18 Wang NP, Zee S, Zarbo RJ, et al. Coordinate expression of cytokeratins 7 and 20 defines unique subsets of carcinomas. Appl Immunohistochem 1995;3:99-107.

19 Vang R, Gown AM, Barry TS, et al. CDX2 versus CK20 and CK7 for distinction of primary ovarian mucinous tumors from metastatic mucinous carcinomas involving the ovary [Abstract]. Mod Pathol 2005;18:207A.

20 Abu-Jawdeh GM, Jacobs TW, Niloff J, et al. Estrogen receptor expression is a common feature of ovarian borderline tumors. Gynecol Oncol 1996;60:301-307.

21 Brown RW, Campagna LB, Dunn JK, et al. Immunohistochemical identification of tumor markers in metastatic adenocarcinoma. A diagnostic adjunct in the determination of primary site. Am J Clin Pathol 1997;107:12-19.

22 Deamant FD, Pombo MT, Battifora H. Estrogen receptor immunohistochemistry as a predictor of site of origin in metastatic breast cancer. Appl Immunohistochem 1993;1:188-192.

23 Dennis JL, Hvidsten TR, Wit EC, et al. Markers of adenocarcinoma characteristic of the site of origin: development of a diagnostic algorithm. Clin Cancer Res 2005;11:3766-3772.

24 Fujimura M, Hidaka T, Kataoka K, et al. Absence of estrogen receptor-alpha expression in human ovarian clear cell adenocarcinoma compared with ovarian serous, endometrioid, and mucinous adenocarcinoma. Am J Surg Pathol 2001;25:667-672.

25 Kaufmann O, Kother S, Dietel M. Use of antibodies against estrogen and progesterone receptors to identify metastatic breast and ovarian carcinomas by conventional immunohistochemical and tyramide signal amplification methods. Mod Pathol 1998;11:357-363.

26 Koshiyama M, Konishi I, Mandai M, et al. Immunohistochemical analysis of p53 protein and $72 \mathrm{kDa}$ heat shock protein (HSP72) expression in ovarian carcinomas. Correlation with clinicopathology and sex steroid receptor status. Virchows Arch 1995;425: 603-609.

27 O’Connell FP, Wang HH, Odze RD. Utility of immunohistochemistry in distinguishing primary adenocarcinomas from metastatic breast carcinomas in the gastrointestinal tract. Arch Pathol Lab Med 2005;129: 338-347.

28 Carano KS, Soslow RA. Immunophenotypic analysis of ovarian and testicular müllerian papillary serous tumors. Mod Pathol 1997;10:414-420.

29 Halperin R, Zehavi S, Dar P, et al. Clinical and molecular comparison between borderline serous ovarian tumors and advanced serous papillary ovarian carcinomas. Eur J Gynaecol Oncol 2001;22:292-296. 
30 Halperin R, Zehavi S, Hadas E, et al. Immunohistochemical comparison of primary peritoneal and primary ovarian serous papillary carcinoma. Int J Gynecol Pathol 2001;20:341-345.

31 Nolan LP, Heatley MK. The value of immunocytochemistry in distinguishing between clear cell carcinoma of the kidney and ovary. Int J Gynecol Pathol 2001;20:155-159.

32 Rosen DG, Huang X, Deavers MT, et al. Validation of tissue microarray technology in ovarian carcinoma. Mod Pathol 2004;17:790-797.

33 Baskaran V, Vij U, Sahni P, et al. Do the progesterone receptors have a role to play in gallbladder cancer? Int J Gastrointest Cancer 2005;35:61-68.

34 Cameron BL, Butler JA, Rutgers J, et al. Immunohistochemical determination of the estrogen receptor content of gastrointestinal adenocarcinomas. Am Surg 1992;58:758-760.

35 Chadha S, Rao BR, Slotman BJ, et al. An immunohistochemical evaluation of androgen and progesterone receptors in ovarian tumors. Hum Pathol 1993;24: 90-95.

36 Chaubert P, Bouzourene H, Saraga E. Estrogen and progesterone receptors and pS2 and ERD5 antigens in gastric carcinomas from the European population. Mod Pathol 1996;9:189-193.

37 Chu PG, Weiss LM. Immunohistochemical characterization of signet-ring cell carcinomas of the stomach, breast, and colon. Am J Clin Pathol 2004;121:884-892.

38 Goldstein NS, Long A, Kuan SF, et al. Colon signet ring cell adenocarcinoma: immunohistochemical characterization and comparison with gastric and typical colon adenocarcinomas. Appl Immunohistochem Mol Morphol 2000;8:183-188.

39 Ko CY, Schmit P, Cheng L, et al. Estrogen receptors in gallbladder cancer: detection by an improved immunohistochemical assay. Am Surg 1995;61:930-933.

40 Koullias GJ, Kouraklis GP, Raftopoulos IS, et al. Increased estrogen receptor and epidermal growth factor receptor gene product co-expression in surgically resected gastric adenocarcinomas. J Surg Oncol 1996;63:166-171.

41 Lagendijk JH, Mullink H, van Diest PJ, et al. Immunohistochemical differentiation between primary adenocarcinomas of the ovary and ovarian metastases of colonic and breast origin. Comparison between a statistical and an intuitive approach. J Clin Pathol 1999;52:283-290.

42 Lee KR, Nucci MR. Ovarian mucinous and mixed epithelial carcinomas of mullerian (endocervical-like) type: a clinicopathologic analysis of four cases of an uncommon variant associated with endometriosis. Int J Gynecol Pathol 2003;22:42-51.

43 Lindgren PR, Cajander S, Backstrom T, et al. Estrogen and progesterone receptors in ovarian epithelial tumors. Mol Cell Endocrinol 2004;221:97-104.

44 Malik IA, Abbas Z, Shamsi Z, et al. Immuno-histochemical analysis of estrogen receptors on the malignant gallbladder tissue. J Pak Med Assoc 1998;48: 123-126.

45 Nash JW, Morrison C, Frankel WL. The utility of estrogen receptor and progesterone receptor immunohistochemistry in the distinction of metastatic breast carcinoma from other tumors in the liver. Arch Pathol Lab Med 2003;127:1591-1595.

46 Ollayos CW, Riordan GP, Rushin JM. Estrogen receptor detection in paraffin sections of adenocarcinoma of the colon, pancreas, and lung. Arch Pathol Lab Med 1994;118:630-632.

47 Perry A, Parisi JE, Kurtin PJ. Metastatic adenocarcinoma to the brain: an immunohistochemical approach. Hum Pathol 1997;28:938-943.

48 Slattery ML, Samowitz WS, Holden JA. Estrogen and progesterone receptors in colon tumors. Am J Clin Pathol 2000;113:364-368.

49 Takeda H, Yamakawa M, Takahashi T, et al. An immunohistochemical study with an estrogen receptor-related protein (ER-D5) in human colorectal cancer. Cancer 1992;69:907-912.

50 Tot T. The role of cytokeratins 20 and 7 and estrogen receptor analysis in separation of metastatic lobular carcinoma of the breast and metastatic signet ring cell carcinoma of the gastrointestinal tract. APMIS 2000; 108:467-472.

51 Xin Y, Li XL, Wang YP, et al. Relationship between phenotypes of cell-function differentiation and pathobiological behavior of gastric carcinomas. World J Gastroenterol 2001;7:53-59.

52 Ronnett B, Gown AM, Barry TS, et al. Utility of immunohistochemistry in determining the site of origin of metastatic mucinous carcinomas involving the ovary [Abstract]. Mod Pathol 2005;18:201A.

53 Cano G, Milanezi F, Leitao D, et al. Estimation of hormone receptor status in fine-needle aspirates and paraffin-embedded sections from breast cancer using the novel rabbit monoclonal antibodies SP1 and SP2. Diagn Cytopathol 2003;29:207-211.

54 Huang Z, Zhu W, Szekeres G, et al. Development of new rabbit monoclonal antibody to estrogen receptor: immunohistochemical assessment on formalin-fixed, paraffin-embedded tissue sections. Appl Immunohistochem Mol Morphol 2005;13:91-95.

55 Theodoropoulos GE, Lazaris AC, Panoussopoulos D, et al. Significance of estrogen receptors and cathepsin $\mathrm{D}$ tissue detection in gastric adenocarcinoma. J Surg Oncol 1995;58:176-183.

56 Alkushi A, Irving J, Hsu F, et al. Immunoprofile of cervical and endometrial adenocarcinomas using a tissue microarray. Virchows Arch 2003;442:271-277.

57 Fujiwara H, Tortolero-Luna G, Mitchell MF, et al. Adenocarcinoma of the cervix. Expression and clinical significance of estrogen and progesterone receptors. Cancer 1997;79:505-512.

58 McCluggage WG, Sumathi VP, McBride HA, et al. A panel of immunohistochemical stains, including carcinoembryonic antigen, vimentin, and estrogen receptor, aids the distinction between primary endometrial and endocervical adenocarcinomas. Int J Gynecol Pathol 2002;21:11-15.

59 Mikami Y, Kiyokawa T, Moriya T, et al. Immunophenotypic alteration of the stromal component in minimal deviation adenocarcinoma ('adenoma malignum') and endocervical glandular hyperplasia: a study using oestrogen receptor and alpha-smooth muscle actin double immunostaining. Histopathology 2005;46:130-136.

60 Staebler A, Sherman ME, Zaino RJ, et al. Hormone receptor immunohistochemistry and human papillomavirus in situ hybridization are useful for distinguishing endocervical and endometrial adenocarcinomas. Am J Surg Pathol 2002;26:998-1006.

61 Toki T, Shiozawa T, Hosaka N, et al. Minimal deviation adenocarcinoma of the uterine cervix has abnormal expression of sex steroid receptors, CA125, and gastric mucin. Int J Gynecol Pathol 1997;16:111-116. 
62 Ballouk F, Boguniewicz A, Ross JS, et al. Image analysis quantification in hormone receptor assay of mucinous carcinoma of the breast. Comparison with biochemical analysis. Anal Quant Cytol Histol 1995; 17:151-156.

63 Honma N, Sakamoto G, Akiyama F, et al. Breast carcinoma in women over the age of 85: distinct histological pattern and androgen, oestrogen, and progesterone receptor status. Histopathology 2003;42: 120-127.

64 Lal P, Tan LK, Chen B. Correlation of HER-2 status with estrogen and progesterone receptors and histologic features in 3,655 invasive breast carcinomas. Am J Clin Pathol 2005;123:541-546.

65 Nadji M, Gomez-Fernandez C, Ganjei-Azar P, et al. Immunohistochemistry of estrogen and progesterone receptors reconsidered: experience with 5,993 breast cancers. Am J Clin Pathol 2005;123:21-27.

66 Qiu W, Mittal K. Comparison of morphologic and immunohistochemical features of cervical microglandular hyperplasia with low-grade mucinous adenocarcinoma of the endometrium. Int J Gynecol Pathol 2003;22:261-265.

67 Dabbs DJ, Landreneau RJ, Liu Y, et al. Detection of estrogen receptor by immunohistochemistry in pulmonary adenocarcinoma. Ann Thorac Surg 2002;73: 403-405.

68 Radzikowska E, Langfort R, Giedronowicz D. Estrogen and progesterone receptors in non small cell lung cancer patients. Ann Thorac Cardiovasc Surg 2002;8:69-73.
69 Shiohara S, Shiozawa T, Shimizu M, et al. Histochemical analysis of estrogen and progesterone receptors and gastric-type mucin in mucinous ovarian tumors with reference to their pathogenesis. Cancer 1997;80: 908-916.

70 Dube V, Roy M, Plante M, et al. Mucinous ovarian tumors of mullerian-type: an analysis of 17 cases including borderline tumors and intraepithelial, microinvasive, and invasive carcinomas. Int J Gynecol Pathol 2005;24:138-146.

71 Rodriguez IM, Irving JA, Prat J. Endocervical-like mucinous borderline tumors of the ovary: a clinicopathologic analysis of 31 cases. Am J Surg Pathol 2004;28:1311-1318.

72 Rutgers JL, Scully RE. Ovarian mullerian mucinous papillary cystadenomas of borderline malignancy. A clinicopathologic analysis. Cancer 1988;61:340348.

73 Shappell HW, Riopel MA, Smith Sehdev AE, et al. Diagnostic criteria and behavior of ovarian seromucinous (endocervical-type mucinous and mixed cell-type) tumors: atypical proliferative (borderline) tumors, intraepithelial, microinvasive, and invasive carcinomas. Am J Surg Pathol 2002;26: 1529-1541.

74 Vang R, Gown AM, Barry TS, et al. Ovarian atypical proliferative (borderline) mucinous tumors: Gastrointestinal and seromucinous (endocervical-like) types are immunophenotypically distinctive. Int J Gynecol Pathol, in press. 